Jurnal Wacana Kesehatan

Volume 4, Nomor 2, Desember 2019

e-ISSN 2544-6251

\title{
STIMULASI KUTANEUS (FOOT MASSAGE)MENURUNKAN SKALA NYERI PASIEN LANSIA DENGAN RHEUMATOID ARTHRITIS
}

\section{CUTANEOUS STIMULATION (FOOT MASSAGE) ON PAIN SCALES IN ELDERLY WITH RHEUMATOID ARTHRITIS}

\author{
Rizki Muliani ${ }^{1}$, Tuti Suprapti², Siti Nurkhotimah ${ }^{3}$ \\ 123 Sekolah Tinggi Kesehatan Bhakti Kencana Bandung \\ e-mail : tutisuprapti12@yahoo.com
}

\begin{abstract}
ABSTRAK
Rheumatoid Arthritis (RA) merupakan salah satu penyakit kronis yang dapat menimbulkan sensasi nyeri pada lansia. Salah satu upaya menangani nyeri non farmakologis adalah dengan stimulasi kutaneus yaitu metode noninvasif dalam mengatasi nyeri pada lansia,stimulasi kutaneus dapat menurunkan nyeri dengan cara mendorong pelepasan endorphin, sehingga memblok transmisi stimulus nyeri serta memberikan block pada transmisi nyeri, serta mengaktifkan endorphine, memperlancar peredaran darah dan membuat relaksasi otot sehinga nyeri berkurang. Penelitianini bertujuan untuk mengetahui pengaruh stimulasi kutaneus(foot massage) terhadap skala nyeri pada lansia dengan rheumatoid arthritis.Metode penelitian menggunakan Pre Experimen dengan pendekatan one grouppretest posttest dengan sampel menggunakan purposive sampling sebanyak 22 orang lansia. Teknik pengumpulan data menggunakan skala nyeri numeric rating scale dan prosedur kerja foot massage dilakukan 1 kali sehariselama 20 menit dalam waktu 5 hari. Analisa data menngunakan Wilcoxon Sign Rank Test. Hasil penelitian menunjukan sebagian kecil lansia mengalami skala nyeri 5 sebelum dilakukan stimulasi kutaneus : foot massage dan sebagian lansia mengalami skala nyeri 3 sesudah dilakukan pemberian stimulasi kutaneus : foot massage. Hasiluji Wilcoxon menunjukan $\mathrm{P}$-value $0.000(\mathrm{P}<0.05)$ sehingga disimpulkan ada pengaruh stimulasi kutaneus(foot massage) terhadap skala nyeri pada lansia dengan rheumatoid arthritis. Oleh karena itu, diharapkan pihak panti untuk membuat SOP foot massage dan perawat dapat menerapkan foot massage sebagai terapi komplementer untuk mengurangi nyeri pada lansia dengan rheumatoid arthritis.
\end{abstract}

Kata kunci :foot massage, Nyeri,Lansia,rheumatoid arthritis

\begin{abstract}
Rheumatoid Arthritis (RA) is a chronic disease that can cause a sensation of pain in the elderly.One effort to deal with non-pharmacological pain is by cutaneous stimulation, which is a noninvasive method in overcoming pain in the elderly, cutaneous stimulation can reduce pain by encouraging the release of endorphins, thereby blocking the transmission of pain stimulus and blocking the transmission of pain, and activating endorphins, accelerating blood circulation.and makes muscle relaxation so that pain is reduced. The purpose of this study was to determine the effect of cutaneous stimulation: foot massage on pain scale in the elderly with rheumatoid arthritis. This study used a Pre Experiment with one group pretest-posttest. Add a hypen. approach with samples using purposive sampling as many as 22 elderly people.Data collection techniques used a numerical rating scale and the foot massage procedure was performed 1 time a day for 20 minutes in 5 days.Analysis of data using the Wilcoxon Sign Rank Test.Wilcoxon test results showed a P-value of $0.000(P<0.05)$ so that it was concluded there was an effect of cutaneous stimulation: foot massage on the pain scale in the elderly with rheumatoid arthritis. Therefore, it is expected that the institution to make SOP foot massage and nurses can apply foot massage as a complementary therapy to reduce pain in the elderly with rheumatoid arthritis.
\end{abstract}

Keywords: foot massage; pain; elderly; rheumatoid arthritis 


\section{PENDAHULUAN}

Lanjut usia merupakan bagian dari proses tumbuh kembang, di mana manusia tidak secara tiba-tiba menjadi tua, tetapi berkembang dari bayi, anak-anak, dewasa, dan akhirnya menjadi tua $^{1}$. Berdasarkan data proyeksi penduduk, diprediksi jumlah penduduk lansia tahun 2020 (27,08 juta), tahun2025 (33,69 juta), tahun 2030 (40,95 juta) dan tahun 2035 (48,19 juta $)^{2}$. Berdasarkan usia kronologis/biologisnya, lanjut usia dibagi menjadi 4 kelompok, yaitu usia pertengahan (middle age) antara usia 45-59 tahun, lanjut usia (elderly) berusia antara 60-74 tahun, lanjut usia tua (old) usia 75-90 tahun, dan usia sangat tua (very old) di atas 90 tahun $^{2}$

Perubahan fisik yang terjadi pada lansia dan merupakan penyakit dengan prevalensi yang cukup besar terdapat pada penyakit muskuloskeletal ${ }^{3}$. Administration of Aging (AOA) menemukan bahwa lansia yang hidup di masyarakat mengalami masalah kronis pada sistem muskuloskeletal, 17\%sarcopenia, osteopenia, sedangkan $40 \%$ pada lansia tersebut mengalami artritis ${ }^{4}$.Sistem muskuloskeletal yang terjadi pada lansia menyebabkan penyakit kronik yang multipel, perubahan fungsi tubuh, dan kelemahan fisik ${ }^{5}$. Perubahan ini terjadi karena jaringan penghubung (kolagen dan elastin), kartilago, otot, dan sendi ${ }^{1}$ Gangguan persendian merupakan keluhan yang sering dikeluhkan lansia dan menempati urutan ke dua $(14,5 \%)$ setelah penyakit kardiovaskuler dalam pola penyakit masyarakat usia $>55$ tahun $^{2}$ Prevalensi penyakit sendi di Indonesia juga cukup tinggi, sebesar 24, $7 \%$. Pada usia 45-54 prevalensinya sebesar 37,2\%, usia 55-64 sebesar 45,0\%, usia 65-74 sebesar 51,9\% dan usia lebih dari 75 sebesar 54,8\% $\%^{6}$.

Salah satu penyakit kronis yang dapat menimbulkan sensasi nyeri pada lansia adalah Rheumatoid Arthritis(RA) merupakan penyakit inflamasi kronis yang dapat mengakibatkan kerusakan pada tulang serta menimbulkan kecacatan, Rheumatoid arthritis menyerang 0,5$1 \%$ populasi dunia dan merupakan penyebab utama kecacatan ${ }^{6}$. Gejala yang paling sering adalah nyeri, pembengkakan dan kekakuan sendi-sendi kecil pada tangan, dan secara progresif nyeri sering dirasakan di lutut ${ }^{7}$

Rasa nyeri pada penderita RA dirasakan pada bagian synovial sendi, sarung tendon, dan bursa akan mengalami penebalan akibat radang yang diikuti oleh erosi tulang dan destruksi tulang sekitar sendi ${ }^{8}$. Nyeri sendi yang ditimbulkan mulai dari skala ringan hingga berat yang dapat mengganggu aktivitas lansia ${ }^{9}$ Tindakan farmakologi untuk menurunkan nyeri menurut dibagi menjadi tiga kategori umum, yaitu anestesi lokal, agen analgesik opioid, dan Nonsteroidal Anti-inflammatory Drugs (NSAIDs).Pemberian obat sebagai penurun nyeri, dengan pemberian obat-obat analgesik seperti pemberian obat anti inflamasi non steroid (OAINS) ${ }^{10}$.

Sedangkan tindakan nonfarmakologis untuk menurunkan nyeri dapat digolongkan menjadi dua kategori, yaitu intervensi stimulasi kutan dan intervensi perilaku kognitif. Intervensi 
stimulasi kutan mempunyai keuntungan yaitu intervensi ini dapat dilakukan pada beragam area, sangat efektif dilakukan pada area distal, proksimal, atau kontralateral terhadap area pemicu nyeri. Sedangkan penerapan intervensi perilaku kognitif pada lansia kurang efektif, karena pada lansia terdapat faktor-faktor yang dapat mengganggu seperti defisit kognitif, depresi berat ${ }^{9}$.

Terapi alternatif untuk mengurangi nyeri pada rheumatoid arthritis dilakukan stimulasi kutaneus yang merupakan metode noninvasif dalam mengatasi nyeri pada lansia ${ }^{9}$. Stimulasi kutaneus merupakan stimulasi kulit yang dilakukan untuk menghilangkan nyeri, bekerja dengan cara mendorong pelepasan endorphin, sehingga memblok transmisi stimulus nyeri. Cara lainnya adalah dengan mengaktifkan transmisi serabut saraf sensori A-beta yang lebih besar dan cepat, sehingga menurunkan transmisi nyeri melalui serabut saraf $\mathrm{C}$ dan A-delta berdiameter kecil sehingga menutup gerbang sinap untuk transmisi impuls nyeri ${ }^{11}$.

Sentuhan dan Massage merupakan teknik integrasi sensori yang mempengaruhi aktifitas sistem saraf otonom. Apabila individu mempersepsikan sentuhan sebagai stimulus untuk relaks, maka akan muncul respon relaksasi. Relaksasi sangat penting dalam membantu klien untuk meningkatkan kenyamanan dan nyeri yang tak berkesudahan ${ }^{11}$. Massage kaki (foot massage) pada kaki membantu dalam pembangunan kembali keseimbangan pada tubuh, hal ini juga membantu dalam meningkatkan aliran darah, mengurangi tekanan darah dan kolesterol serta dapat mengurangi nyeri. Beberapa penelitian menggambarkan bahwa foot massage adalah salah satu metode yang paling umum dari terapi komplementer yang dapat menurunkan nyeri ${ }^{12}$. Manfaat footmassage dapat memberikan block pada transmisi nyeri, dan mengaktifkan endorphine atau senyawa penawar alamiah dalam sistem kontrol desenden dan membuat relaksasi otot sehinga nyeripun berkurang.

\section{METODE}

Jenis penelitian yang digunakan dalam penelitian ini adalah metode pre-eksperimental dengan pendekatan One Group Pretest-Posttest Design tanpa kelompok kontrol. Populasi dalam penelitian ini adalahadalah lansia yang mengalami Rheumatoid Arthritis di Panti Sosial Rehabilitasi Lanjut Usia dan Pemeliharaan Makam Pahlawan berjumlah 150 orang. Sampel penelitian dari bulan januari- februari 2018 sebanyak 38 orang. Pengambilan sampel pada penelitian ini menggunakan teknik purposive sampling, Adapun kriteria yang ditentukan dalam penelitian ini adalah Lansia dengan tingkat nyeri ringan dan sedang, belum mengkonsumsi obat analgesik dan yang sudah mengkonsumsi obat analgesik setelah 2 jam, usia > 60 tahun, tidak mengalami penurunan fungsi kognitif dan mental, tidak memiliki luka terbuka atau kerusakan pada kaki. Sehingga sampel dalam penelitian ini berjumlah 22 lansia. Instrument yang digunakan untuk mengukur nyeri menggunakan kuesioner skala Numeric 
Rating Scale (NRS) dan untuk massage menggunakan prosedur kerja Foot Massage Pengukuran skala nyeri dilakukan sebelum dilakukan massage, kemudian dilakukan foot massage 1 kali sehari pada pagi hari dengan durasi 20 menit selama 5 hari berturut-turut. Setelah foot massage hari ke 5 dilakukan post test untuk mengukur skala nyeri setelah dilakukan foot massage.

Analisa data menggunakan Wilcoxon sign rank test, karena hasil uji normalitas data menggunakan Shapiro wilk, didapatkan hasil pre test 0.000 dan post test 0.000 yang artinya data tidak berdistrusi normal.

\section{HASIL}

Hasil penelitian dapat dilihat melalui tabel dibawah ini :

Tabel 1

Skala Nyeri Sebelum Dan Sesudah Dilakukan Tindakan Foot Massage, $n=22$

\begin{tabular}{ccccc}
$\begin{array}{c}\text { Skala } \\
\text { Nyeri }\end{array}$ & & Sebelum & \multicolumn{2}{c}{ Sesudah } \\
& & & & \\
\cline { 2 - 5 } & F & $\%$ & F & $\%$ \\
\hline 0 & 0 & 0 & 8 & 36,4 \\
1 & 1 & 4,5 & 0 & 0 \\
2 & 5 & 22,7 & 3 & 13,6 \\
3 & 3 & 13,6 & 10 & 45,5 \\
4 & 5 & 22,7 & 1 & 4,5 \\
5 & 6 & 27,3 & 0 & 0 \\
6 & 2 & 9,1 & 0 & 0 \\
7 & 0 & 0 & 0 & 0 \\
8 & 0 & 0 & 0 & 0 \\
9 & 0 & 0 & 0 & 0 \\
10 & 0 & 0 & 0 & 0 \\
\hline Total & 22 & 100,0 & 22 & 100,0 \\
\hline
\end{tabular}

Sumber data primer, 2018

Berdasarkan tabel 1 dapat diketahui bahwa sebagian kecil (27,3 \%) lansia yang mengalami rheumatoid arthritis sebelum dilakukan foot massage memiliki skala nyeri 5, dan sesudah dilakukan foot massage sebagian $(45,5 \%)$ lansia memiliki skala nyeri 3.

Tabel 2

\section{Tingkat Nyeri Sebelum Dan Sesudah Dilakukan Tindakan Foot Massage $\mathrm{n}=\mathbf{2 2}$}

\begin{tabular}{|c|c|c|c|c|}
\hline \multirow{2}{*}{$\begin{array}{l}\text { Tingkat } \\
\text { Nyeri }\end{array}$} & \multicolumn{2}{|c|}{ Sebelum } & \multicolumn{2}{|c|}{ Sesudah } \\
\hline & $\mathrm{F}$ & $\%$ & $\mathrm{~F}$ & $\%$ \\
\hline $\begin{array}{l}\text { Tidak } \\
\text { nyeri }\end{array}$ & 0 & 0,0 & 8 & 36,4 \\
\hline $\begin{array}{l}\text { Nyeri } \\
\text { ringan }\end{array}$ & 9 & 40,9 & 13 & 59,1 \\
\hline $\begin{array}{l}\text { Nyeri } \\
\text { sedang }\end{array}$ & 13 & 59,1 & 1 & 4,5 \\
\hline $\begin{array}{l}\text { Nyeri } \\
\text { berat }\end{array}$ & 0 & 0,0 & 0 & 0 \\
\hline Total & 22 & 100,0 & 22 & 100,0 \\
\hline \multicolumn{5}{|c|}{$\begin{array}{l}\text { Berdasarkan tabel } 2 \text { dapat diketahui bahwa } \\
\text { lansia yang mengalami rheumatoid arthritis } \\
\text { sebelum dilakukan foot massage mengalami } \\
\text { nyeri sedang }(59,1 \%) \text {, dan sesudah dilakukan } \\
\text { foot massage sebagian }(59,1 \%) \text { lansia } \\
\text { mengalami nyeri ringan. }\end{array}$} \\
\hline \multicolumn{5}{|c|}{$\begin{array}{l}\text { Hasil uji Wilcoxon untuk melihat pengaruhi } \\
\text { didapat hasil sebagai berikut : }\end{array}$} \\
\hline \multicolumn{5}{|c|}{$\begin{array}{c}\text { Tabel } 3 \\
\text { Pengaruh Stimulasi Kutaneus (Foot Massage) } \\
\text { Terhadap Skala Nyeri Pada Lansia } \\
\text { Dengan Rheumatoid Arthritis } \\
\mathbf{n}=\mathbf{2 2}\end{array}$} \\
\hline $\begin{array}{c}\text { Tindakan } \\
\text { terapi }\end{array}$ & $\begin{array}{l}\text { Mean } \\
\text { rank }\end{array}$ & Mean & $\mathrm{Z}$ & $\begin{array}{c}\mathrm{P}- \\
\text { value }\end{array}$ \\
\hline Sebelum & 3.73 & $-1,909$ & -4.030 & 0.000 \\
\hline Sesudah & 1.82 & & & \\
\hline
\end{tabular}


Berdasarkan tabel 3 diketahui bahwa diperoleh p-value $(0.000)<0.05$ artinya ada pengaruh skala nyeri sebelum dan sesudah dilakukan foot massage.

\section{PEMBAHASAN}

Berdasarkan hasil penelitian pada tabel 2 dapat diketahui bahwa sebelum dilakukan tindakan foot massage terhadap nyeri rheumatoid arthritis pada lansia sebagian $(59,1 \%)$ responden mengalami nyeri sedang dan (40.9\%) lainnya mengalami nyeri ringan. Dari hasil penelitian yang dilakukan sebelum tindakan foot massage didapatkan bahwa lansia mengalami nyeri sendi lutut. Sifat nyeri adalah subyektif, nyeri yang dirasakan individu berbeda-beda dan hanya dapat digambarkan oleh individu yang mengalami nyeri itu sendiri.

Rheumatoid arthritismerupakan peradangan akibat reaksi autoimun dalam jaringan sinovial yang melibatkan proses fagositosis. Dalam prosesnya, dihasilkan enzim-enzim dalam sendi, yang selanjutnya akan memecah kolagen sehingga terjadi edema, proliferasi membran sinovial dan akhirnya terjadi pembentukan pannus. Pannus yang meradang akan menghancurkan tulang rawan dan menimbulkan erosi tulang, menimbulkan gambaran klinis nyeri dan kekauan yang diikuti pembengkakan, instabilitas dan dekstruksi sendi. Akibatnya adalah menghilangnya permukaan sendi yang akan mengganggu gerak sendi, otot akan merasakan nyeri akibat serabut otot mengalami perubahan degeneratif dengan menghilangnya kemampuan elastisitas otot ${ }^{4}$.

Nyeri merupakan akibat dari proses inflamasi dan peningkatan tekanan didalam sendi yang menekan ujung syaraf. Menurut ${ }^{11}$ gejala nyeri sendi terjadi karena $44 \%$ lansia mengalami radang sendi, Adapun faktor-faktor yang mempengaruhi nyeri adalah usia, jenis kelamin, budaya, ansietas, pengalaman masa lalu tentang nyeri, efek placebo, keluarga, pola koping.

Dalam penelitian ini didapatkan bahwa lansia berusia di 75-90 tahun (old) yang mengalami nyeri rheumatoid arthritis. Hasil penelitian ini menunjukan bahwa semakin bertambah usia seseorang akan mengalami beberapa perubahan dalam diri mereka secara psikologis. Sedangkan jenis kelamin didapatkan bahwa sebagian besar lansia perempuan mengalami rheumatoid arthritis ini sebagai akibat dari keterlibatan hormon estrogen. Hormon ini merangsang autoimun, sehingga menimbulkan rheumatoid arthritis

Sesudah dilakukan tindakan foot massage terhadap nyeri rheumatoid arthritis pada lansia, 8 orang responden tidak nyeri $(36,4 \%), 13$ orang responden nyeri ringan $(59,1 \%)$, dan 1 orang responden nyeri sedang (4,5\%). Artinya ada perbedaan skala nyeri sebelum dan sesudah diberikan tindakan foot massage.

Massage yang dilakukan pada kaki bagian bawah, dimulai dari pemijatan pada kaki yang diakhiri pada telapak kaki, diawali dengan memberikan gosokan pada permukaan punggung kaki, dimana gosokan yang berulang 
menimbulkan peningkatan suhu di area gosokan yang mengaktifkan sensor syaraf kaki sehingga terjadi vasodilatasi pembuluh darah dan getah bening yang mempengaruhi aliran darah meningkat, sirkulasi darah menjadi lancar, pasokan oksigen ke jaringan yang inflamasi menjadi adekuat sehingga dapat menurunkan nyeri. Foot massage memperbaiki sirkulasi darah pada otot sehingga mengurangi nyeri dan inflamasi.

Perubahan nyeri yang terjadi pada responden dalam penelitian ini menunjukan bahwa penurunan nyeri sangat bervariasi. Hasil evaluasi menyatakan bahwa lansia mengatakan lebih nyaman setelah di pijat, nyeri dan kaku berkurang. Pijat kaki adalah sebuah teknik dimana kedua kaki orang yang akan dipijit dipegang dengan beberapa posisi berbeda, dipijat-pijat dengan lembut dan beraturan untuk mengetahui respon relaksasinya.

Foot massage mampu memberikan efek relaksasi yang mendalam, mengurangi rasa sakit, ketidaknyamanan secara fisik, dan meningkatkan tidur pada seseseorang. Foot massage dapat memberikan efek untuk mengurangi rasa nyeri karena pijatan yang diberikan menghasilkan stimulus yang lebih cepat sampai ke otak dibandingkan dengan rasa sakit yang dirasakan, sehingga meningkatan sekresi serotonin dan dopamin. Sedangkan efek pijatan merangsang pengeluaran endorfin, sehingga membuat tubuh terasa rileks karena aktifitas saraf simpatis menurun.
Hal ini sebagaimana dengan penelitian yang dilakukan oleh ${ }^{13}$ dalam penelitiannya tentang efektifitas foot massage terhadap nyeri pada pasien dengan masalah musculoskeletal hasil penelitian menunjukan bahwa terdapat pengaruh foot massage terhadap nyeri . Penelitian tersebut membuktikan bahwa terapi foot massage dapat digunakan untuk menurunkan nyeri, termasuk nyeri kronis seperti nyeri punggung dan sendi lutut.

Berdasarkan hasil penelitian pada tabel 3 diatas, dapat diketahui bahwa ada pengaruh skala nyeri sebelum dan sesudah dilakukan foot massage. Diperoleh mean sebelum dilakukan foot massage3.73 sedangkan setelah dilakukan foot massage didapatkan hasil mean 1.82, dengan nilai $\mathrm{z}-4.030$ artinya terdapat penurunan yang signifikan.

Mekanisme foot massage yang dilakukan pada kaki bagian bawah dimulai dari pemijatan pada kaki yang diakhiri pada telapak kaki diawali dengan memberikan gosokan pada permukaan punggung kaki, dimana gosokan yang berulang menimbulkan peningkatan suhu diarea gosokan yang mengaktifkan sensor syaraf kaki sehingga terjadi vasodilatasi pembuluh darah dan getah bening yang mempengaruhi aliran darah meningkat, sirkulasi darah menjadi lancar ${ }^{14}$. Foot massage memperbaiki sirkulasi darah pada otot sehingga mengurangi nyeri dan inflamasi. Hal ini sejalan dengan patofisiologi nyeri rheumatoid arthritis, dimana nyeri rheumatoid arthritis timbul karena adanya inflamasi. 
Foot massagemengaktifkan aktifitas parasimpatik kemudian memberikan sinyal neurotransmiter ke otak, organ dalam tubuh, dan bioelektrik ke seluruh tubuh. Sinyal yang di kirim ke otak akan mengalirkan gelombang alfa yang ada di dalam otak. Impuls saraf yang dihasilkan saat melakukan foot massage diteruskan menuju hipotalamus untuk menghasilkan Corticotropin Releasing Factor (CRF). CRF merangsang kelenjar pituitary untuk meningkatkan produksi Proopioidmelanocortin (POMC) sehingga medulla adrenal memproduksi endorfin. Endorfin yang disekresikan ke dalam peredaran darah dapat memberikan efek analgesic alami terhadap jaringan yang mengalami peradangan. Saat evaluasi hari terakhir, lansia mengatakan bahwa pada saat bangun pagi mereka tidak merasakan kaku dan nyeri pada daerah sendi, terutama sendi lutut. Sebanyak dua orang lansia yang masih memiliki skala nyeri tetap pada saat post test, mereka tidak mengalami penurunan skala nyeri, hal ini disebabkan karena usia lansia tersebut sudah tua dibandingkan dengan lansia yang lain serta mereka sudah menderita rheumatoid arthritis sejak lama (> 1 tahun), dimana usia yang lebih tua rentan dengan nyeri kronis yang dirasakan. Hal ini sesuai dengan penelitian yang dilakukan ${ }^{14}$ bahwa orang yang lebih tua rentan terhadap rasa nyeri yang kronis, yang berlangsung lebih dari 3 bulan, dimana rasa sakit ini salah satunya timbul karena gangguan muskuloskeletal.
Pada saat penelitian, terdapat 5 lansia mengalami nyeri sedang dan 1 lansia mengalami nyeri ringan yang mengkonsumsi obat analgesik (piroxicam) sebelum dilakukan tindakan foot massage. Didapatkan hasil skala nyeri pre dan post mengalami penurunan yang signifikan, hal ini dikarenakan fungsi obat analgesik yang mampu menurunkan nyeri serta kombinasi dari foot massage yang dilakukan dapat melengkapi proses penurunan skala nyeri pada lansia. Oleh karena itu terapi farmakologi memang tidak dapat dipisahkan, namun untuk penggunaan dosisnya dapat disesuaikan dengan kondisi fisiologis lansia dan foot massage ini dapat dijadikan sebagi terapi komplementer untuk menurunkan rasa nyeri pada lansia.

\section{KESIMPULAN}

Stimulasi kutaneus (foot massage)ada pengaruh terhadap skala nyeri pada lansia dengan rheumatoid arthritis. Diharapkan pihak panti dapat membuat SOP foot massage sebagai tindakan non farmakologi untuk menurunkan nyeri,serta mengadakan pelatihan bagi perawat tentang foot massage, diharapkan perawat dapat mengikuti pelatihan foot massage serta menerapkan foot massage sebagai tindakan terapi komplementer untuk mengurangi nyeri pada lansia dengan rheumatoid arthritis.

\section{DAFTAR PUSTAKA}

1. Azizah, 2011,Keperawatan Lanjut Usia, Graha Ilmu, Yogyakarta 
2. WHO, 2018, Musculoskeletal conditions.http://www.thelancet.com/pdfs/jo urnals/lancet/PIIS01406736\%2817\%2932154-2.pdf. Diakses pada 24 Maret 2018.

3. Kemenkes RI, 2017, Pusat Data Dan Informasi, www.depkes.go.id.

4. Alcaras. Gualilo. Pernaute, 2013, Musculoskeletal Disorders, Http://www.Thelancet.com. Diakses pada 20 April 2018.

5. Kneale, Julia D, 2011, Keperawatan Ortopedi \& Trauma. Alih Bahasa Egi Komara Yudha Et Al Ed 2, EGC, Jakarta.

6. Rastoogi \& Meek, 2013, Management Of Chronic Pain In Elderly, Frail Patient: Finding A Suitable, Personalized Method Of Control Dove Medical Press Ltd, 37:46

7. Smolen, Josef S. Aletaha, Daniel. Mcinnes, Iain B, 2016, Rheumatoid Arthritis. Lancet; 388: 2023-38. Diakses Pada 24 Maret 2018.

8. Riskesdas, 2013, Badan Penelitian Kesehatan RI Tahun 2013. Diakses Pada April 2018 Depkes.go.id.

9. Mass, L. Meridean, et al. Alih Bahasa Renata Komalasari, et al, 2011, Asuhan Keperawatan Geriatric: Diagnosis Nanda, Kriteria Hasil Noc, \& Intervensi Nic, EGC, Jakart

10. Smeltzer \& Bare, 2010, Buku Ajar Keperawatan Medikal Bedah, EGC, Jakarta

11. Syamsyuhidajat R, Karnadiharja W, Prasetyono T O H., Rudiman R, 2010, Buku Ajar Ilmu Bedah Syamsyuhidajat De Jong Ed 2, EGC, Jakarta.

12. Potter, P. A., \& Perry, A, G, 2010, Fundamental of Nursing : Fundamental Keperawatan buku 3 edisi7, Salemba Medika, Jakarta.

13. Kaur, J.., Kaur, S., Dan Bhardwaj, N, 2012, Effect Of Foot Massage And Reflexologi On Phisiological Parameters Of Critically Ill Patients. Nursing and Midwifery Research Journal, 8(3), 223-233. Diakses Pada 10 April 2018.

14. Swales, Catherine \& Christopher Bulstrode, 2015, At a Glance Rheumatologi, Ortopedi, dan TraumaEdisi Kedua. Alih Bahasa Huriawati Hartanto, dkk, Penerbit Erlangga, Jakarta.
15. Kristanto, T, 2011, Pengaruh Terapi Back Massage Terhadap Intensitas Nyeri Reumatik Pada Lansia Diwilayah Puskesmas Pembantu Karang Asem

16. Cooney, Law. Matschke, Lenmey, Moore, Ahmad, Et All., 2011, Benefits Of Exercise In Rheumatoid Arthritis, Sage- Hindawi Acces To Research. 
Wacana Kesehatan Vol. 4 , No.2 , Desember 2019 